\title{
Evaluation of the Third Party Logistics Listing Corporation Efficiency
}

\author{
Yin Hang \\ Engineering Training Center \\ Shenyang Aerospace University \\ Shenyang, China \\ Yinhang@sau.edu.cn
}

\begin{abstract}
Based on DEA (data envelopment analysis) method, this article systematically studies efficiency of third party logistics enterprise in China, and mainly discusses the effectiveness and its influencing factors of third-party listed logistics companies. The paper develops an econometric model, calculates the technical efficiency value as the dependent variable based on the DEA method, and conducts regression analysis using the variables such as quality of human resource management, salary payment system, relative assets scale, and business concentration that can't be included in the input-output model as the independent variable. The paper makes it clear the way and degree of influence on the operating efficiency of third-party logistics enterprises by quality of human resources, payroll compensation system, relative scale of assets and business concentration.
\end{abstract}

Keywords- DEA; third-party logistics; operating efficiency; comprehensive evaluation

\section{RESEARCH SIGNIFICANCE TO THE EFFICIENCY EVALUATION OF THIRD-PARTY LISTED LOGISTICS COMPANIES}

With the rapid development of economy, the competition of logistics industry is fierce in China. In the face of the fierce competition, how to meet the diversified needs of customers and better develop the logistics companies? The common problem for the third-party logistics companies in China is how to objectively evaluate the efficiency of the logistics company, which is also the global concern for the third-party listed logistics companies at home and abroad.

The rapid development of third-party listed logistics companies accelerates the development of global economy, and promotes the development of third-party logistics. Logistics companies optimize the allocation of global resources. In the process of integration such as production, trade and investment, logistics companies drive lots of potential logistics market; the internal requirements for third-party logistics services come along in order to reduce operating costs and improve operational efficiency. The demand of third-party logistics market has increased rapidly and more comprehensive and professional services are needed from the third-party logistics.

As a rising industry, the operation method of logistics industry is still in its early stages, and the efficiency evaluation system is underdeveloped. The traditional efficiency evaluation pays too much attention to net profit margin, and ignores other factors that have a major impact on the normal operation of logistics enterprises and longterm profitability. Nowadays, combing with the characteristics of its own, the third-party listed logistics companies need urgently to solve the problem of establishing a reasonable set of operational efficiency evaluation methods for third-party logistics companies and scientifically evaluating the company's operating efficiency.

\section{BASIC THEORY OF THIRD-PARTY LOGISTICS}

The third party logistics rises after the traditional buyer logistics and the seller logistics. According to this definition, the service providers of traditional transportation enterprises, storage enterprises, and customs brokers can be viewed as the third-party logistics companies.

On the level of theory or the actual operation, in theory circle or the circle of industrial and commercial business, different experts have different opinions on the third-party logistics. On the whole, it includes contract logistics, integrated logistics and the third-party logistics beyond the supply and demand.

The first party is the demand of logistics service; the second party is a provider of logistics service; the thirdparty logistics is to provide service for the first party collecting the resources and capacities of the second party. The third-party logistics is more professional.

\section{DEA METHOD-EVALUATING OPERATIONAL EFFICIENCY}

\section{A. Basic theory of DEA method}

DEA (data envelopment analysis) is a new field. Based on the concept of relative efficiency, DEA is a kind of nonparametric statistical method used to evaluate decisionmaking units for multi-input and multi-output, and whether technology effectively. The basic idea is to treat each evaluated unit as a DMU, and numerous DMU make up the group to be evaluated. Through comprehensive analysis of input and output, evaluate and calculate with weight of each DMU input and output indicators as the variables, and determine whether each DMU is DEA effective according to the distance of each DMU and effective production cutting edge.

Due to needless estimations of parameters in advance, DEA method can avoid the subjective factors that other methods do not have. Secondly, it has great superiority in 
the aspects of operation and error measurement. DEA as been widely applied to the decision and evaluation in listed logistics companies in recent years.

In logistics companies, one logistics production process can be seen as a unit, which is the activity of inputting a number of factors of production and outputting a certain number of logistics service. Although the specific content of each activity is different, the common goal is trying to obtain the biggest benefits. The input and output are realized by a series of decisions, so output is the final result of decisions. This unit is called a decision making unit (DMU).Each decision making unit represents certain economic significance, and the basic feature of DMU is having a certain input and output, realizing their own decision value in the process of transforming the input into output.

\section{1) The meaning of $\mathrm{DMU}$}

The concept of decision making unit can be a company, in which the input is the company's house, working capital, mechanical equipment, materials and technical personnel, and the output is all kinds of finished goods. DEA method does not need to estimate parameters in advance. DEA method is a new nonparametric statistical analysis method, a kind of multi-objective decision method, and a kind of evaluation methods studying multi inputs and multi outputs. It has strong practical applications, and can do without knowing the function relationship between input and output and projected parameters in advance. As an objective and multi-index decision-making method, DEA does not need the weight of each indicator given in advance or determine the weight coefficient by prior judgment. Therefore, the analysis of DEA will not be affected by the subjective factors, merely affected by the objective cause on the evaluation results, which can more reflect the actual situation of DMU. With many advantages in efficiency measure for enterprises mentioned above, DEA method is chosen to evaluate the operational efficiency of third-party listed logistics companies.

\section{2) Production possibility set}

In a production activity, suppose that the input vector of one DMU is: $x=\left(x_{1}, x_{2}, \ldots, x_{m}\right)^{T}$, the output vector is: $y=\left(y_{1}, y_{2}, \ldots, y_{s}\right)^{T}$, so we can simply use $(\mathrm{x}, \mathrm{y})$ to show the entire production of DMU; the set $T=\{(x, y)$ I the output $\mathrm{y}$ can be produced by $\mathrm{x}\}$ is production possibility set formed by all possible production activities. According to the actual situation and convenience of researching problems, generally it is assumed that the production possibility set satisfies the four axioms: convexity shows that $\mathrm{T}$ is a set of convex; cone shows that $\mathrm{K}$ times of original output is possible if $\mathrm{K}$ times of the original input is the new input; inefficiency indicates that it's always possible to increase input or decrease output for the production on the basis of original production activities; the minimality shows that the production possibility set $\mathrm{T}$ is the intersection of all the set satisfying axioms.

\section{3) Basic thoughts}

Suppose that there are $\mathrm{n}$ same types $\mathrm{DMU}^{j}(j=1,2, \ldots, \mathrm{n})$. Each DMU has $\mathrm{m}$ kinds of input and s kinds of output, so input and output of each DMU can be expressed by vector:

$$
\begin{gathered}
X_{j}=\left(x_{1 j}, x_{2 j}, \ldots, x_{i j}, \ldots, \mathrm{x}_{m j}\right)^{T} \mathrm{f} 0 \\
i=1,2, \ldots, m ; \quad j=1,2, \ldots, n \\
Y_{j}=\left(y_{1 j}, y_{2 j}, \ldots y_{k j}, \ldots y_{s j}\right)^{T} \mathrm{f} 0 \\
k=1,2, \ldots, s ; j=1,2, \ldots, n
\end{gathered}
$$

For one decision making unit $\mathrm{DM}_{j 0}\left(1 \leq j_{0} \leq n\right)$ we can construct two input-oriented and output-oriented linear programming models:

$L P_{1}$

$$
\text { (input-oriented): seek one kind of linear }
$$
combination of DMU ${ }^{j 0}\left(1 \leq j_{0} \leq n\right)$, under the condition of maintaining the output of $\mathrm{DMU}^{j 0}$, find the minimum input, and check whether the input is smaller than the original input. The relevant models:

$$
\begin{aligned}
& \operatorname{MinZ} \\
& \text { s.t. } \sum_{j=1}^{n} \lambda_{j} x_{i j} \leq x_{i j 0} Z \quad, \quad i=1,2, \ldots, m \\
& \sum_{j=1}^{n} \lambda_{j} y_{k j} \geq y_{k j 0} \quad, \quad k=1,2, \ldots, s \\
& \lambda_{j} \geq 0, \quad Z \geq 0, \quad j=1,2, \ldots, \mathrm{n}
\end{aligned}
$$

Obviously, the optimal solution $z^{\prime} \leq 1, Z^{\prime}<1$ shows that the input of new combined DMU is much smaller, and the original DMU ${ }^{j 0}$ is ineffective. Therefore, to judge the validity of one DMU using DEA method is relative to the value of a set of practical observations.

\section{B. DEA model for the measurement of efficiency}

1) CRS model-DEA model for the measurement of technical efficiency

CRS model is the most basic DEA model. Suppose that

there are $\mathrm{n}$ DMU, and each $\mathrm{DMU}^{j}$ has $\mathrm{m}$ kinds of input and s kinds of output. Recorded as:

$$
\begin{gathered}
X_{j}=\left(x_{1 j}, x_{2 j}, \ldots, x_{i j}, \ldots, \mathrm{x}_{m j}\right)^{T} \mathrm{f} 0 \\
i=1,2, \ldots, m ; j=1,2, \ldots, n \\
Y_{j}=\left(y_{1 j}, y_{2 j}, \ldots y_{k j}, \ldots y_{s j}\right)^{T} \mathrm{f} 0
\end{gathered}
$$

$k=1,2, \ldots, s \quad ; \quad j=1,2, \ldots, n$

Of which, ${ }^{x_{i j}}$ is the total input to ith input index by jth decision-making unit; ${ }^{y_{k j}}$ is the total output to kth output index by jth decision-making unit, besides $x_{i j}>0 ; \quad y_{k j}>$ 0 .

We need to grant appropriate weight for the input and output indexes, set the weight of $x_{i}$ as $v_{i}, y_{i}$,s weight as $u_{k}$, recorded as:

$$
v_{i}=\left(\mathrm{v}_{1}, \mathrm{v}_{2}, \ldots, \mathrm{v}_{m}\right)^{T}
$$




$$
\begin{gathered}
u_{k}=\left(\mathrm{u}_{1}, \mathrm{u}_{2}, \ldots, \mathrm{v}_{m}\right)^{T} \\
h_{j}=\frac{u^{T} y_{j}}{v^{T} x_{j}}=\frac{\sum_{k-1}^{s} u_{k} y_{k j}}{\sum_{i=1}^{m} v_{t} x_{j}}, \mathrm{j}=1,2, \ldots, \mathrm{n}
\end{gathered}
$$

Now, we evaluate the DMUj0 $\left(1 \leq j_{0} \leq n\right)$. Suppose that the weight coefficient $\mathrm{u}$ and $\mathrm{v}$ is the variable, the efficiency evaluation index is the goal, and all the efficiency indexes of DMU $h_{j} \leq 1,(\mathrm{j}=1,2, \ldots, \mathrm{n})$ is the constraint. The so-called C2R model is :

$$
\begin{gathered}
\max \frac{\sum_{k=1}^{s} u_{u} y_{k j}}{\sum_{i=1}^{m} v_{i} x_{i j}}=v_{j o} \\
\text { S.T } \frac{\sum_{k=1}^{s} u_{k} y_{k j}}{\sum_{i=1}^{m} v_{i} x_{i j}} \leq 1, j=1,2, \ldots, n \\
u_{k} \geq 0, k=1,2, \ldots, s \\
v_{i} \geq 0, i=1,2, \ldots, m
\end{gathered}
$$

The is a problem of fractional programming, let

$$
\begin{aligned}
& t=\frac{1}{v^{T} x_{0}} \\
& \omega=t v \\
& \mu=t u
\end{aligned}
$$

The above formula can be transformed into a problem of equivalent linear programming:

$$
\begin{aligned}
& \max u^{T} y_{0}=\bar{V}_{p} \\
& \quad \text { (P) } \quad S . T . \omega^{T} x_{j}-\mu^{T} y_{j} \geq 0, j-1,2, \ldots, n \\
& \omega^{T} x_{0}=1 \\
& \omega \geq 0, \mu \geq 0
\end{aligned}
$$

According to the duality theory of linear programming and newly introduced slack variable $s^{+}, s^{-} \geq 0$, we can obtain the dual linear programming model of $(\mathrm{P})$ as: $\min \theta$

(D)

$$
S . T . \sum_{j=1}^{n} \lambda_{j} x_{j}+s^{-}=\theta x_{0}
$$

$$
\begin{aligned}
& \sum_{j=1}^{n} \lambda_{j} y_{j}-s^{+}=y_{0} \\
& \lambda_{j} \geq 0, j=1,2, \ldots, n \\
& s^{+} \geq 0, s^{-} \geq 0
\end{aligned}
$$

The efficiency value of CRS model is technical efficiency, whose economic meaning is the actual investment proportion on the basis of DMU with best performance in the samples when output level of DMU in the ith remains the same. $1-\theta$ is the multi-input proportion of DMU in the ith, i.e. the largest proportion of investment that can be reduced. In particular, it's divided into the following three cases:

$$
\text { When } \theta=1, s^{+}=s^{-}=0 \text {, we say } D M U_{j 0} \text { is DEA }
$$

effective. In other words, the obtained $y_{0}$ is optimized on the basis of original input $x_{0}$ in the economic system composed by the $\mathrm{n}$ decision-making units.

When $\theta=1$, and $s^{+} \neq 0$ or $s^{-} \neq 0$, we say $D M U_{j 0}$ is weakly-efficient. By this time, if $s^{+}=0, s^{-} \neq 0$, it shows that the actual $\mathrm{n}$ decisionmaking units can be combined. Comparing the newly obtained DMU and original $D M U_{j 0}$, we can decrease part rather than the whole of input of original $D M U_{j 0}$, and maintain the same output. If $s^{+}=0, s^{-}=0$, comparing the newly obtained DMU and original $D M U_{j 0}$, we can increase part rather than the whole of output under the condition of the same original $D M U_{j 0}$ input.

When $\theta<1$, we say DMU ${ }^{j 0}$ is DEA ineffective. In the economic system combined by $\mathrm{n}$ decision-making units, we can maintain the original output $y_{0}$ through decreasing all the input components to the $\theta$ proportion of original

$$
\text { input }{ }^{x_{0}} \text { by a combination. }
$$

2) VRS model-DEA model for measuring pure technical efficiency

Under the condition of constant return to scales, the assumption of CRS model is implied by DMU; increasing the investment proportion and expanding the size of the output, which simply means the size of the decision making units, won't affect its efficiency. However, this assumption is very strict, and it won't work in some cases. If it's not perfect competition, and affected by economic environment and the industry or policy, the DMU is hard to run in ideal conditions. In this case, the assumption of constant return to scales is obviously not in conformity with the actual situation, and results in not all the judged DMU on the optimum scale, and the confusion of technical efficiency and scale efficiency. The assumption of variable returns to scale makes the computation efficiency remove the influence of scale efficiency, so that the efficiency is pure technical efficiency.

By adding the convexity assumption $\sum_{i=1}^{n} \lambda_{i}=1$, CRS model can be easily modified as VRS model,

$$
\min \theta^{*}
$$

$$
S . T . \sum_{j=1}^{n} \lambda_{j} x_{j}+s^{-}=\theta^{*} x_{0}
$$




$$
\begin{aligned}
& \sum_{j=1}^{n} \lambda_{j} y_{j}-s^{+}=y_{0} \\
& \sum_{i=1}^{n} \lambda_{i}=1 \quad, \quad \lambda_{j} \geq 0, \mathrm{j}=1,2, \ldots, \mathrm{n} \\
& s^{+} \geq 0, s^{-} \geq 0
\end{aligned}
$$

Technical efficiency=pure technical efficiency* scale efficiency, i.e. $T E_{C R S}=T E_{V R S} * S E$. Using CRS and VRS model, we can calculate the technical efficiency and pure technical efficiency of DMU, and obtain scale efficiency of the DMU.

\section{COUNTERMEASURES AND SUGGESTIONS TO IMPROVE EFFICIENCY OF THIRD-PARTY LISTED LOGISTICS COMPANIES IN CHINA}

\section{A. Improve the quality of human resources}

Introduction of professional logistics management talents, the enterprise must have a comprehensive understanding about their existing state of human resources, especially the advantages and disadvantages of their existing staffs. The company must make a comprehensive planning about their future direction of development, and realize the relationship between current human resource environment and the scale to be achieved in the future.

To strengthen enterprise trainings, including the training of senior management staff and basic business personnel. In the trainings, the key part is the training of senior management personnel, and the others are the innovation of management and technology, and the updates of senior executives' thought. The company can have a better development only if the senior executives have advanced ideas and advanced management methods. As the saying goes, there is only poor leadership, but no outdated mass. To completely change the company staff's ideology, we need to cultivate enterprise culture first, as the concept of basic staff decides the future of the enterprise.

\section{B. Improve business concentration}

Reducing cost in logistics as much as possible is necessary for the rising listed logistics companies to be well developed. For third-party logistics companies, the outsourcing business must have absolute advantages in quality and speed. When providing logistics services to the customers, the third-party listed logistics companies must consider their practical ability and the diversification of customer needs, conduct a comprehensive integration combining with the business characteristics of both sides, provide better logistics services and improve customer satisfaction.

Centralization strategy is to focus all the ability of enterprise on a selected area because of different logistics demand in different fields. The centralization strategy not only refers to the concentration of company's direction of business development, but also the concentration in enterprise recruitment and training, establishment of the organizational structure, acquirement of related operation qualifications and other aspects. Thus, it will become a professional third-party listed logistics companies.

\section{Improve incentive mechanism including pay treatment}

The pay treatment mechanism of third-party listed logistics companies has more to do with the operation efficiency of the enterprise. The healthier the pay treatment mechanism, the higher the operation efficiency; they are of positive relevance. The requirement of the company's senior managers is to know the basic needs of workers and implement the incentive; the company will meet the needs of employees as far as possible, not only confined to the big or small salary. Good staffs remain, and tough staffs get fired. What's more, the enterprises determine reasonable salary level, regularly investigate salary, and collect latest salary information so as to remain the salary competitive in the industry. Meanwhile, make the pay and benefits diversified and humanized, reflect the value of intellectual labor on the policies and systems, attach importance to human resources management, and provide corresponding salary to its contribution. Put scientific research and technology input as the elements of distribution; employees who make outstanding contribution to the company can get more money, so as to make the company's distribution much more uniform.

\section{Expand the scale of assets}

The scale of assets of third-party listed logistics companies has no obvious relationship with its operational efficiency, but most of the technical inefficiency of thirdparty listed logistics companies is due to the scale inefficiency. According to the current situation of increasing returns to scale for most of the third-party listed logistics companies, our suggestions and countermeasures are moderately expanding the scale of assets, achieving scale economy and better development for third-party listed logistics companies.

\section{CONCLUSION AND PROSPECT}

As a whole, technical efficiency of the entire thirdparty logistics industry is generally low. From the point of each type of enterprise, the average technical efficiency of port enterprises is the highest, followed by the transport companies, and the technical efficiency of storage enterprise is the worst. From the point of each enterprise's location, overall technical efficiency of third-party logistics companies with main source of business in the south is higher than that in the north.

Technical inefficiency of enterprise is likely to be caused by pure technical inefficiency. It may also be caused by larger or smaller scale of production or both.

At present, the scale of most of the third-party logistics enterprises is relatively too small to its efficiency in our country, but this study can't show clearly its optimum size, which needs further studies.

This paper discusses the study of third-party logistics enterprise's operating efficiency using a nonparametric method of data envelopment analysis (DEA).

In the later study, method of stochastic frontier (SAF), free distribution method (DAF), thick frontier approach (TAF), and other parametric methods can be considered to use for the study of operational efficiency of enterprises. What's more, give the comparisons in order to better evaluate the operational efficiency of the third-party logistics enterprise, and guide enterprises for better operation and management. 
All manuscripts must be in English. These guidelines include complete descriptions of the fonts, spacing, and related information for producing your proceedings manuscripts. Please follow them and if you have any questions, direct them to the production editor in charge of your proceedings at Conference Publishing Services (CPS): Phone +1 (714) 821-8380 or Fax +1 (714) 761-1784.

This template provides authors with most of the formatting specifications needed for preparing electronic versions of their papers. All standard paper components have been specified for three reasons: (1) ease of use when formatting individual papers, (2) automatic compliance to electronic requirements that facilitate the concurrent or later production of electronic products, and (3) conformity of style throughout a conference proceedings. Margins, column widths, line spacing, and type styles are built-in; examples of the type styles are provided throughout this document and are identified in italic type, within parentheses, following the example. PLEASE DO NOT RE-ADJUST THESE MARGINS. Some components, such as multi-leveled equations, graphics, and tables are not prescribed, although the various table text styles are provided. The formatter will need to create these components, incorporating the applicable criteria that follow.

\section{REFERENCES}

[1] Wang Ruogang, Feng Yingjun, Yang Chang. Study on the dynamic performance evaluation of logistics based on DEA method [J]; Journal of Shenyang Architectural University (Natural Science Edition)

[2] Quan Chunguang, Cheng Xiaojuan. Performance evaluation of Chinese logistics enterprises based on DEA [J]. Logistics engineering and management 2010, 5:40-42

[3] Ding Xiaolong, Wang Fuzhong, Li Zhong. Modern logistics management [M]. Peking University, 2010.

[4] Liu Hua, Meng Jianhua. Introduction to modern logistics management [M]. Tsinghua University Press, 2010.

[5] Zang Xiaoning. Study on the efficiency evaluation of logistics enterprise based on DEA model [D]. University of Science and Technology of China, 2009

[6] Wang Shuhong, Song Malin. Analysis on the production efficiency of logistics enterprise based on DEA method set [J]. Logistics technology, 2010, 8:52-55.

[7] Wang Xuhui, Xu Jian. Efficiency evaluation of our listed logistics enterprise based on supper efficiency CCR-DEA [J]. Finance and Trade Research, 2009, 6:117-124

[8] Wang Anjin, Gong Bengang, Gui Yunmiao. The method AHPTOPSIS for comprehensive evaluation of logistics enterprise performance and application [J] Journal of Anhui engineering institute of technology, 2009, 4:73-76.

[9] Yu Shufeng, Study on the fuzzy comprehensive evaluation of modern logistics enterprise performance $[\mathrm{J}]$. Logistics engineering and management 2009.9:41-44

[10] Huang Xiangrong, Xie Ruhe Evaluation of food cold chain logistics enterprise performance based on entropy weight and grey relevance [J].Journal of Guangzhou University(Natural Science Edition), 2009,4:87-90

[11] Shen Yuan, Qi Shixiong. Performance evaluation of our listed logistics companies based on DEA method [J]. Logistics technology, 2009, 8:97-100

[12] [12] Hao-Tien Liu, Wei-Kai Wang. An integrated fuzzy approach for provider valuation and select in third-party logistics [J].2009(36)

[13] Cheng Lun. Arrange research on comprehensive performance evaluation of listed enterprises based on DEA/FA model- take logistics enterprise as an example [D] Economy and trade scholar of Hebei, 2010.
[14] Sun Keyang, Zhao Yifei. Operational efficiency evaluation of listed port companies based on factor analysis and SE-DEA [J]. Journal of Shanghai Maritime University, 2010, 1:67-71

[15] Rao Tiantian, Lv Tao. Evaluation and analysis of large-scale coal enterprise operational efficiency based on DEA [J]. China mining, 2009, 8:27-30

[16] Zhu Xiaoli. Study on the operational efficiency evaluation of global telecom based on DEA [D]. Beijing University of Posts and Telecommunications. 2009

[17] LI-CHEN LIU DEA APPROACH FOR THE CURRENT AND THE CROSS PERIOD EFFICIENCY FOR EVALUATING THE VOCATIONAL. EDUCATION [J].International Journal of Information Technology \&Decision Making, 2009, 3 (2) : 353374. 